\title{
O brincar como instrumento facilitador para o relato de eventos privados relacionados à hospitalização
}

\section{The playing as a facilitator for the report of private events related to the hospitalization}

\section{El acto de jugar como instrumento facilitador para el relato de eventos privados relacionados a la hospitalización}

\author{
Elyoneida Maria de Moraes Ávila', Yanne Luna de Azevedo²
}

\begin{abstract}
[1] Universidade Federal do Maranhão - UFMA, São Luís, Maranhão [2] Universidade CEUMA, São Luís, Maranhão I Título abreviado: Brincar e o relato de privados | Endereço para correspondência: | Email: elyoneida.m.avila@gmail.com I doi: 10-18761/PAC.TAC.2019.009 | Nota: Nós declaramos que a pesquisa redigida no manuscrito não recebeu qualquer tipo de financiamento de terceiros, sendo de inteira responsabilidade das autoras o custeio da execução da pesquisa. Declaramos que não possuímos conflito de interesses de ordem pessoal, comercial, acadêmico, político e financeiro no manuscrito. Declaramos ainda que a pesquisa seguiu rigorosamente os cuidados éticos de pesquisa e publicação, que contou com o consentimento livre e esclarecido dos participantes e que foi aprovada pelo Comitê de Ética em Pesquisa (CEP) do Hospital Universitário da Universidade Federal do Maranhão - HUUFMA e pelo Comitê Nacional de Ética em Pesquisa - CONEP
\end{abstract} sob o número do parecer 086/2014.

Resumo: A Terapia Analítico-Comportamental Infantil (TACI) é um modelo psicoterápico baseado na Análise do Comportamento, e tem como público-alvo as crianças. A TACI utiliza os recursos lúdicos durante o processo psicoterápico. A utilização desse recurso se dá, dentre outros motivos, porque as crianças ainda não têm repertório verbal plenamente desenvolvido que as permitam se beneficiar de uma terapia puramente verbal. A presente pesquisa propõe identificar o relato de eventos privados relacionados à hospitalização de duas crianças internadas emitidos nas interações com recursos lúdicos e nas interações puramente verbais. Participaram da pesquisa dois meninos, ambos de oito anos, internados na ala pediátrica de um hospital universitário. Utilizou-se em cada encontro um recurso lúdico diferente, criado especificamente para a interação, sendo usado ora na metade inicial da interação, ora na metade final. Os encontros ocorreram no leito em que cada participante estava internado e tiveram seus áudios gravados. A partir dos dados coletados, percebeu-se que os participantes conseguiram relatar alguns eventos privados na interação com o recurso lúdico que não conseguiram emitir na interação puramente verbal. Percebeu-se ainda que o desenvolvimento de atividades lúdicas durante as interações estabeleceu e fortaleceu mais facilmente a relação entre pesquisadora e participantes.

Palavras-chave: eventos privados; Terapia Analítico-Comportamental Infantil; brincar; hospitalização infantil. 
Abstract: The Child Behavioral-Analytic Therapy (CBAT) is a psychotherapeutic model based on Behavior Analysis, and it has the target audience of children. The CBAT uses the recreational resources during the psychotherapeutic process. The use of this resource is given, among other reasons, because children still do not have a fully developed verbal repertoire that allows them to benefit from a purely verbal therapy. The present research proposes to identify the report of private events related to the hospitalization of two hospitalized children emitted in the interactions with playful resources and in the purely verbal interactions. Two boys participated in the research, both eight years old, and hospitalized in the pediatric ward of a university hospital. A different play resource was used at each meeting, created specifically for the interaction, being used now in the initial half of the interaction, now in the final half. The meetings took place in the bed where each participant was hospitalized and had their audios recorded. From the data collected, it was noticed that the participants were able to report some private events in the interaction with the playful resource that they could not emit in the purely verbal interaction. It was also concluded that the use of recreational resources during the interactions established and strengthened more easily the trust relationship between researcher and participants.

Keywords: private events; The Child Behavioral-Analytic Therapy; to play; child hospitalization.

Resumen: La Terapia Analítico-Comportamental Infantil (TACI) es un modelo psicoterápico basado en el Análisis del Comportamiento, y tiene como público objetivo a los niños. La TACI utiliza los recursos lúdicos durante el proceso psicoterápico. La utilización de este recurso se da, entre otros motivos, porque los niños aún no tienen un repertorio verbal plenamente desarrollado que les permita beneficiarse de una terapia puramente verbal. La presente investigación propone identificar el relato de eventos privados relacionados a la hospitalización de dos niños internados emitidos en las interacciones con recursos lúdicos y en las interacciones puramente verbales. Participaron de la investigación dos niños, ambos de ocho años, internados en el barrio pediátrico de un hospital universitario. Se utilizó en cada encuentro un recurso lúdico diferente, creado específicamente para la interacción, siendo utilizado ora en la mitad inicial de la interacción, ora en la mitad final. Los encuentros ocurrieron en el lecho en que cada participante estaba internado y tuvieron sus audios grabados. A partir de los datos recolectados, se percibió que los participantes consiguieron expresar verbalmente algunos eventos privados en la interacción con el recurso lúdico que no consiguieron emitir en la interacción puramente verbal. Se percibió tambien que el desarrollo de actividades lúdicas durante las interacciones estableció y fortaleció más fácilmente la relación entre investigadora y participantes.

Palabras-clave: eventos privados; Terapia Analítico-Comportamental Infantil; jugar; hospitalización infantil. 


\section{Considerações sobre eventos privados a partir da perspectiva Behaviorista Radical}

O Behaviorismo foi inaugurado no início do século XX por John B. Watson (1878-1958), que afirmou que a Psicologia deveria ser redefinida como o estudo dos comportamentos (Skinner, 2006). A iniciativa de Watson buscava conferir à Psicologia o mesmo status de cientificidade desfrutado por outras ciências naturais, estabelecendo como métodos a observação e a experimentação (Tourinho, 2009). Concebeu o comportamento observável (aquele que pode ser observado por mais de uma pessoa) como objeto de investigação da Psicologia (Moreira \& Hanna, 2012).

No entanto, na ânsia de transformar a Psicologia em ciência, Watson dispensou de seus estudos todos os eventos que não eram observáveis diretamente por outras pessoas. Dessa forma, ele abdicou do estudo da então chamada consciência (Baum, 2019). Sua proposta ficou conhecida mais tarde como Behaviorismo Metodológico e vários sistemas explicativos foram desenvolvidos a partir de suas proposições. Convencionou-se chamar todos esses sistemas de behavioristas por elegerem o comportamento como objeto de estudo (Tourinho, 2009).

De todos os behavioristas pós-Watson, B.F. Skinner (1904-1990) é o mais conhecido. Ele propôs uma nova versão do behaviorismo, o qual intitulou de Behaviorismo Radical em oposição à proposta de Watson (Baum, 2019). Ao contrário do Metodológico, o Behaviorismo Radical não nega a possibilidade da auto-observação ou do autoconhecimento, porém questiona a natureza daquilo que é sentido ou observado (Skinner, 2006). Isso porque, para Skinner (2006), a única característica que distingue os eventos públicos daqueles que acontecem no "mundo sob a pele" é a quantidade de pessoas que pode relatar o fenômeno. Ele considera que um evento que ocorre no mundo privado de uma pessoa, como um pensamento, por exemplo, é tão físico quanto falar sobre esse pensamento.

Marçal (2010) pontua que o termo Radical vem de raiz e arrisca fazer a analogia da origem do termo com a parte da planta que não é diretamente observável, exatamente para reconhecer que esta é uma diferença fundamental entre o Behaviorismo Radical e os modelos behavioristas anteriores: a consideração dos eventos privados (parte não observável do comportamento humano) em seus estudos.

Skinner (2006) também diverge das abordagens psicológicas tradicionais ao rejeitar a função causal dos processos mentais. De acordo com o autor, atribuir a causa do comportamento à chamada consciência não permitiria investigar quais aspectos estariam envolvidos na determinação de um comportamento. Segundo Skinner (1991), esse tipo de explicação dá a falsa impressão de que se está explicando algo, quando na verdade, não se está explicando nada.

A partir dessa concepção, o Behaviorismo Radical cessa com o dualismo mente-corpo que fora herdado da Filosofia, afastando a metafísica do saber científico (Costa, 2002; Marçal, 2010). Para Skinner (1961, 2006), não existe nada de misterioso com respeito ao mundo privado; o ser humano faz parte do mundo natural e, tanto os eventos públicos quanto os privados ocorrem na mesma dimensão natural. Assim, as mesmas leis que descrevem as relações funcionais dos eventos públicos, se aplicam aos eventos privados (Marçal, 2010). A única distinção entre os eventos públicos e privados reporta-se a questão da acessibilidade (Skinner, 1961). Os eventos privados só podem ser acessados diretamente pelo próprio indivíduo que os está experimentando (Skinner, 2006).

A compreensão de que tantos os eventos públicos quanto os privados possuem a mesma dimensão física significa que ambos são igualmente passíveis de serem estudados. Dessa forma, tantos os públicos quanto os privados fazem parte dos fenômenos elencados pelos analistas do comportamento como parte de seu escopo de investigação científica e de atuação clínica (Rico, Golfeto, \& Hamazaki, 2012).

Segundo Skinner (2003), o mundo privado de cada indivíduo se constrói a partir das relações que ele estabelece com a comunidade verbal. Costa (2002) pontua que, apesar de Skinner não aceitar a causalidade interna, este autor assume que em algumas situações o evento privado pode controlar uma resposta pública, como por exemplo, quanto uma condição corporal controla uma descrição verbal. Contudo, apesar de exercer controle da resposta, 
esse evento privado nunca será visto como autônomo na determinação do comportamento. A relação entre um evento privado e público deve ser explicada a partir das variáveis externas e não internas. Por exemplo, um indivíduo que sente dor de cabeça (evento privado) relata a alguém a dor que está sentindo. Entretanto, a decisão de relatar ou não a sensação dolorosa, a forma como irá descrever tal sensação e para quem o indivíduo irá contar sobre o assunto são variáveis que independem do estímulo privado "dor de cabeça".

A compreensão de que há variáveis ambientais envolvidas no que a pessoa sente e pensa leva os analistas do comportamento a tentar identificar tais variáveis e a modificá-las para obter mudança nos padrões comportamentais do indivíduo, tanto públicos quanto privados (Rico, Golfeto, \& Hamazaki, 2012). Segundo Skinner (2006, p.31), os relatos do mundo interior são pistas "para o comportamento passado e as condições que o afetaram, para o comportamento atual e as condições que o afetam, e para as condições relacionadas com o comportamento futuro".

É inquestionável a relevância que o mundo privado tem para o Behaviorismo Radical. Neste sentido, é fundamental saber como a pessoa se sente ou pensa em determinada situação. Mas nesse ponto, chega-se a uma questão relevante: se o que a pessoa sente e pensa são eventos privados dos quais a comunidade não tem acesso direto, então como saber o que o indivíduo está pensando ou sentindo? (Rico et al., 2012). Segundo Skinner (2006) e Naves e Ávila (2018), a comunidade tem acesso a esses eventos através do relato da pessoa e por meio dos seus comportamentos emocionais, que consistem em manifestações públicas como chorar e expressões faciais.

\section{A Terapia Analítico- Comportamental Infantil e o uso do brincar como forma de acesso aos eventos privados}

A Terapia Analítico-Comportamental Infantil (TACI) é um modelo psicoterápico que tem como base a filosofia do Behaviorismo Radical e a ciência Análise do Comportamento. O público-alvo desse modelo são as crianças que participam de forma direta no processo psicoterápico. A TACI objetiva, dentre outros aspectos, a promoção de mudanças em comportamentos-alvo; a análise de comportamentos verbais; e a análise de eventos privados. (Naves \& Ávila, 2018)

A TACI utiliza durante todo o processo psicoterápico diversos recursos terapêuticos, particularmente os recursos lúdicos (Naves \& Ávila, 2018). Esses recursos abrangem atividades plásticas e gráficas (como desenhos, pintura, modelagem, recortes, dobraduras); jogos; dramatizações; propostas de fantasias; histórias; utilização de bonecos e animais; dentre outros (Del Rey, 2012; Gadelha \& Menezes, 2004)

Dentro do contexto da clínica infantil, percebe-se que a criança normalmente apresenta dificuldade em relatar seus comportamentos como fazem os adultos, isso porque ela ainda não tem repertório de habilidades sociais e de linguagem física e motora desenvolvidas de forma que possa se beneficiar de uma terapia puramente verbal (Del Prette, 2006).

Além da limitação própria da idade, outros aspectos dificultam o relato das crianças sobre situações-problema que tenham vivenciado. Em seu trabalho, Regra (2000) ressalta que a criança tem dificuldade em falar sobre seus sentimentos desagradáveis; apresenta limitação para identificar e nomear seus próprios sentimentos; tem medo de que a verbalização de seus sentimentos acarrete desaprovação do terapeuta; e demonstra preocupação se seus sentimentos serão comunicados aos pais.

Essas especificidades, características do atendimento ao público infantil, exigiram que os terapeutas desenvolvessem novas estratégias para o "pequeno cliente" se expressar além do relato puramente verbal. Reconheceu-se então, a relevância da utilização do brincar como alternativa de atendimento a esse público (Conte \& Regra, 2012).

O uso do brincar nos atendimentos com o público infantil pode ocorrer em diversos momentos e para múltiplos fins. Pode ser utilizado nas entrevistas, no estabelecimento da relação criança-psicólogo, nas avaliações e nas intervenções (Del Prette \& Meyer, 2012).

Del Prette e Meyer (2012) pontuam que o brincar favorece a obtenção de informações com a criança, pois na interação há redução do contato olho a olho quando o psicólogo e a criança estão 
olhando e manuseando brinquedos; há redução da semelhança entre essa interação e as conversas mais 'sérias', que usualmente a criança tem com adultos; e o brincar pode gerar sensações de prazer, incompatíveis com as sensações desagradáveis que podem estar associadas a certos relatos sobre o cotidiano.

$\mathrm{Na}$ Análise do Comportamento, considera-se que os comportamentos emitidos durante o brincar podem dar pistas sobre as contingências que ocorrem fora do contexto psicoterápico (Guerrelhas, Bueno, \& Silvares, 2000; Naves \& Ávila, 2018). Além disso, o brincar também é um importante recurso que contribui para emissão de eventos privados da criança. (Naves \& Ávila, 2018; Soares, Moura, \& Prebianchi, 2003). Através da brincadeira, o terapeuta e a própria criança podem analisar os comportamentos e identificar as contingências que o determinam. E partir dessa análise, a criança pode alterar sua relação com o ambiente (Guerrelhas et al., 2000).

\section{A utilização do brincar no contexto da hospitalização infantil}

A experiência da hospitalização é uma situação crítica e delicada que não passa despercebida. Nesse novo contexto, a criança internada se depara com uma intensa privação de reforçadores - afastamento da sua vida cotidiana e dos entes queridos, perda de privacidade e autonomia, entre outros - e tem contato com várias situações aversivas, como procedimentos invasivos, adequação as regras hospitalares e restrições impostas pela doença. Acrescenta-se a essa realidade a necessidade de permanecer no mesmo ambiente com pessoas até então desconhecidas, como os profissionais do hospital e outros pacientes (Dias, Baptista, \& Baptista, 2003; Ferreira, 2006; Moraes \& Enumo, 2008).

Botega (2012) pontua que quase todas as crianças hospitalizadas apresentam alguma reação a essa experiência, e destaca a ansiedade, a depressão, o apego exagerado aos pais, a diminuição da autoestima, o mau rendimento escolar e a não adesão ao tratamento como as queixas mais frequentes. Carvalho e Begnis (2006) e Doca (2009) destacam alterações de humor e relacionamento social, alterações do sono, alterações alimentares e agressividade como possíveis respostas a hospitalização .
Em um estudo com 18 crianças internadas com câncer, Hostert, Enumo, e Loss (2014) identificaram através de uma escala para avaliação de problemas comportamentais e emocionais que fora aplicada com o cuidador de cada criança, que 11 participantes $(61,1 \%)$ precisavam de atendimento psicológico ou psiquiátrico por apresentarem problemas comportamentais. Nesse estudo, medo (37,2\%), dificuldade de alimentação $(27,9 \%)$ e dificuldade de sono $(23,3 \%)$ foram os comportamentos que apresentaram respostas mais frequentes. Os autores (Hostert et al., 2014) também pontuam que a ocorrência de tais comportamentos podem estar relacionados com o impacto da hospitalização e do tratamento do câncer nestas crianças.

A utilização dos recursos lúdicos proporciona alterações no ambiente hospitalar e pode auxiliar a criança a elaborar estratégias de enfrentamento da hospitalização, favorecendo melhor aceitação ao tratamento (Barros \& Lustosa, 2009; Simões, Yamamoto, Silva, \& Silva, 2010). Essas atividades lúdicas podem ser utilizadas no ambiente hospitalar com o objetivo de ocupar o tempo ocioso da criança e aproximar os pequenos pacientes do seu ambiente normal, o da brincadeira. Segundo Soares et al. (2003), brincar durante a hospitalização pode ser apontado como um dos fatores que acelera a recuperação da criança, ela contribui para a diminuição da permanência no hospital e reduz o custo da hospitalização.

Além de ser um passatempo, as atividades lúdicas podem ser utilizadas como instrumento de intervenção. A utilização desses recursos pelos profissionais atuantes no hospital, como médicos, enfermeiros e terapeutas ocupacionais, pode fazer com que a criança descreva mais claramente as experiências e sentimentos relativos à hospitalização, permitindo intervenções que auxiliem no manejo de contingências que geram ansiedade e auxiliando, por exemplo, na adesão ao tratamento (Del Prette, 2006; Mitre \& Gomes, 2004; Hostert et al., 2014).

Como mencionado anteriormente, os recursos lúdicos são por si sós instrumentos importantes para o enfrentamento da hospitalização infantil. Porém, seus resultados podem ser ampliados quando utilizados nos atendimentos psicológicos hospitalares. Segundo Dias, Baptista, \& Baptista (2003), o suporte psicológico dentro do hospital 
objetiva ao paciente uma melhor expressão e compreensão dos próprios comportamentos, buscando amenizar e até anular as alterações comportamentais prejudiciais apresentadas durante a sua estadia no hospital. Neste contexto, o brincar pode ser utilizado pelo psicólogo para acessar os comportamentos da criança, especialmente os eventos privados. Enquanto forma de expressão, ele pode ser relevante para compreender como a criança está se sentindo e o que ela está pensando sobre sua doença e sobre a hospitalização.

Considerando a eficácia já demonstrada, da utilização de recursos lúdicos como estratégia de investigação e intervenção na TACI, o presente trabalho pretende identificar o relato de eventos privados relacionados à hospitalização de duas crianças internadas emitidos nas interações com recursos lúdicos e nas interações puramente verbais.

\section{Método}

\section{Caracterização da amostra}

Participaram desta pesquisa dois meninos, ambos com oito anos de idade. Para garantir a confidencialidade dos participantes, foram utilizados nomes fictícios. Davi se internou por complicações hepáticas, com suspeita de colestose crônica (diminuição ou interrupção do fluxo de bílis) e hepatite B. Jorge se internou por complicações cardíacas motivadas por cardiopatia congênita. Até o início da pesquisa, Davi estava com 47 dias de internação e João, com 58 dias.

\section{Local da pesquisa}

A pesquisa ocorreu na Clínica Cirúrgica Pediátrica de um Hospital Universitário em São Luís - MA. As interações com as crianças foram realizadas no leito em que os participantes estavam internados.

\section{Instrumento e materiais}

Foram utilizados: roteiros de entrevista semiestruturados, recursos lúdicos, aplicativo gratuito de smartphone para gravar as interações e um notebook para transcrição das mesmas. Todos os recursos lúdicos foram confeccionados pelas pesquisadoras especificamente para as interações desta pesquisa.
Foram elaborados dois roteiros de entrevista: um para aplicar com o respectivo responsável legal de cada participante, e o outro para utilizar com as crianças. O roteiro aplicado aos responsáveis legais era composto por dezoito questões, divididas em três temáticas: informações básicas sobre a criança; história da vida da criança antes da hospitalização; e dados da hospitalização. O roteiro aplicado às crianças era composto por nove questões divididas em duas temáticas: história de vida da criança antes da hospitalização; e informações sobre a hospitalização.

\section{Procedimento}

\section{Seleção dos participantes}

A seleção dos participantes foi feita a partir da triagem dos prontuários hospitalares. Foram selecionadas para a pesquisa, crianças que atenderam os seguintes critérios: (a) estar internado na Clínica Cirúrgica Pediátrica do Hospital; (b) não apresentar comprometimento neurológico; (c) não ter previsão de alta durante o período da coleta dos dados; (d) consentimento dos acompanhantes responsáveis e dos pacientes para participar da pesquisa. Foram selecionadas inicialmente seis crianças que atendiam aos critérios. No entanto, como deveriam ser selecionadas apenas duas crianças para a pesquisa, primeiramente foram abordados dois responsáveis. À medida que havia o consentimento ou não para o menor participar da pesquisa, dirigia-se a outro responsável. Para obter as duas respostas positivas, foram abordados quatro dos seis responsáveis.

\section{Considerações éticas}

O convite à participação na pesquisa foi feito primeiramente ao responsável legal de cada criança. Após o aceite destes, questionou-se o interesse de cada criança em participar do estudo. Foi solicitada, aos responsáveis, a assinatura do Termo de Consentimento Livre e Esclarecido - TCLE. No TCLE constam todos os direitos dos representantes legais e dos participantes, além de informações sobre a pesquisa. Aos participantes menores de idade, foi solicitada a assinatura do Termo de Assentimento Livre e Esclarecido - TALE. Assim como no TCLE, o TALE apresentou, com lingua- 
gem acessível aos participantes, todas as informações fundamentais para que eles tomassem conhecimento da pesquisa. O projeto de pesquisa foi submetido e aprovado pelo Comitê de Ética do Hospital Universitário em que a pesquisa foi realizada (Protocolo 086/2014).

\section{Coleta de dados}

A coleta de dados foi feita por uma das pesquisadoras e realizada em quatro encontros com média de duração de trinta minutos cada. Todos os encontros tiveram seus áudios gravados para posterior transcrição e análise.

Antes dos encontros com os participantes, foi feita a entrevista com cada responsável legal para levantar informações sobre a rotina e a relação das crianças com o brincar antes e durante a hospitalização. Além da entrevista, realizou-se antes de todos os encontros, um breve levantamento com os responsáveis legais para identificar qualquer acontecimento no intervalo entre os encontros que pudesse alterar o comportamento das crian- ças, como por exemplo, a execução de procedimento invasivo ou piora do quadro clínico. Com o mesmo objetivo, foi realizada a leitura diária do prontuário hospitalar de cada participante antes de cada interação.

Foram elencados objetivos para cada um dos encontros. A entrevista com o cada participante foi realizada no primeiro encontro. Os temas abordaram questões relacionadas à experiência da hospitalização. Cada encontro foi subdividido em dois momentos: metade do encontro foi realizado com o uso do brincar; e a outra metade, sem a atividade lúdica, de forma puramente verbal. O momento do brincar foi alternado durante os encontros: ora era utilizado na metade inicial, ora na metade final. A alternância do momento do brincar foi utilizada com objetivo de evitar que o comportamento da criança ficasse sob controle dessa sequência.

Os objetivos de cada encontro e o momento da utilização dos recursos lúdicos foram organizados conforme Tabela 1:

\section{Tabela 1- Programação dos encontros}

\begin{tabular}{l|l|l|l}
\hline \multirow{2}{*}{ Encontro } & Objetivo do encontro & Momento da utilização do recurso \\
\cline { 3 - 4 } & Metade inicial & Metade final \\
\hline $\begin{array}{l}\text { Primeiro } \\
\text { encontro }\end{array}$ & $\begin{array}{l}\text { Entrevista para levantar informações sobre a rotina } \\
\text { das crianças e sobre o comportamento de brincar, } \\
\text { antes e durante a hospitalização. }\end{array}$ & Sem recurso lúdico & Com recurso lúdico \\
\hline $\begin{array}{l}\text { Segundo } \\
\text { encontro }\end{array}$ & $\begin{array}{l}\text { Obter relatos de eventos privados relacionados à } \\
\text { doença e suas implicações para a criança }\end{array}$ & Com recurso lúdico & Sem recurso lúdico \\
\hline $\begin{array}{l}\text { Terceiro } \\
\text { encontro }\end{array}$ & $\begin{array}{l}\text { Obter relatos de eventos privados relacionados ao } \\
\text { ambiente e os procedimentos hospitalares }\end{array}$ & Sem recurso lúdico & Com recurso lúdico \\
\hline $\begin{array}{l}\text { Quarto } \\
\text { encontro }\end{array}$ & $\begin{array}{l}\text { Obter relatos de eventos privados que abordem a } \\
\text { relação do paciente com equipe de profissionais } \\
\text { do hospital e com as outras crianças. }\end{array}$ & Com recurso lúdico & Sem recurso lúdico
\end{tabular}

Fonte: Elaborado pelas autoras.

Os recursos utilizados em cada encontro, bem como uma breve descrição de como eles foram utilizados, estão expostos a seguir:

\section{Primeiro encontro}

Para esse encontro escolheu-se utilizar um desenho para a criança pintar. Enquanto o participante desenvolvia a atividade, estabeleceu-se o diálogo. A imagem era de uma criança deitada em um leito de hospital sendo cuidada por um profissional, que remete a imagem de um médico ou enfermeiro.

A imagem foi retirada da internet e sofreu algumas alterações. $\mathrm{Na}$ imagem original, paciente e profissional estavam com expressões que sugeriam tristeza. Buscou-se alterar a imagem de modo a deixar as expressões mais neutras possíveis para não 
sugestionar aspectos aversivos à criança, o que poderia alterar suas respostas durante a interação.

\section{Segundo encontro}

No segundo encontro escolheu-se a atividade de fantasia. Nessa atividade o cachorrinho de plástico, chamado de Clóvis, estava doente e os participantes foram convidados a inventar uma estorinha para ele.

\section{Terceiro encontro}

No terceiro encontro confeccionou-se um jogo de trilha e um dado. A brincadeira teve como jogadores a pesquisadora e o participante. Para que pudesse avançar o número de casas apontadas no dado, cada jogador deveria responder uma pergunta feita pelo outro jogador. Caso o jogador não soubesse responder a pergunta, ele tinha duas opções: pagava uma prenda para avançar ou permanecia na casa em que estava no momento. Foram exemplos de prendas propostas: citar cinco desenhos animados preferidos; falar a palavra tigre dez vezes e imitar um cachorro. Como o jogo de trilha possuía quinze casas, construiu-se um dado que ia até o numeral três para gerar maior quantidade de jogadas.

\section{Quarto encontro}

Para o quarto encontro, utilizou-se imagens que ilustravam as pessoas com as quais os participantes tinham contato dentro hospital e figuras de estrelas amarelas. Os participantes foram instruídos a demonstrar o quanto eles gostavam de cada pessoa das imagens dando estrelinhas para elas, sendo nenhuma estrela para "não gosto" e cinco estrelas para "gosto muito". Foram avaliados pelos participantes: as crianças que estavam internadas no mesmo quarto que o participante; os acompanhantes das outras crianças do quarto; os médicos; as enfermeiras; a "tia" da brinquedoteca; e os funcionários que realizam a limpeza do quarto.

\section{Análise dos dados coletados}

As interações entre a pesquisadora e os participantes tiveram seus áudios gravados e posteriormente transcritos para análise das verbalizações. A partir das transcrições de cada encontro, buscou-se identificar a verbalização de eventos privados relacionados à hospitalização emitidos pelas crianças nos dois momentos da interação: com e sem recurso lúdico. Utilizou-se os conceitos da Análise do Comportamento para analisar os dados obtidos nesta pesquisa.

\section{Resultados e Discussão}

Os resultados e a discussão foram organizados em dois tópicos: (A) Levantamento de informações dos participantes a partir da entrevista com os responsáveis legais; e (B) Relatos de eventos privados obtidos nos encontros com e sem uso de recurso lúdico.

\section{(A) Levantamento de informações dos participantes a partir da entrevista com os responsáveis legais}

\section{Entrevista com a mãe de Davi}

Davi, gênero masculino, oito anos. Mora com o pai, a mãe e os três irmãos. Frequentava o $4^{\circ}$ ano do ensino fundamental no momento da pesquisa. Davi não teve experiência com psicólogo anterior à internação e ainda não havia tido contato com o setor de psicologia do hospital até então. A única internação anterior a esta aconteceu poucos meses antes, em outro hospital infantil. O motivo da internação atual de Davi foi para fazer biópsia no fígado para investigar quadro de hepatite $B$.

Antes de se internar, Davi brincava com os três irmãos em casa e nas proximidades da residência. As atividades mais comuns eram futebol e pipa. No ambiente hospitalar, Davi jogava no tablet, tinha alguns brinquedos e interagia com as crianças que estavam internadas próximas ao seu leito. Ele não frequentava a brinquedoteca pois a mãe temia que ele contraísse outra doença e prolongasse sua permanência no hospital.

\section{Entrevista com a mãe de Jorge}

Jorge, gênero masculino, oito anos. Filho único, mora apenas com a mãe em um povoado do Maranhão. Estava cursando o terceiro ano do fundamental no turno vespertino e passava as manhãs em casa com a mãe, que é dona de casa. A mãe informou que o pai de Jorge mora em outro município do mesmo estado. Jorge também não teve experiências prévias com psicólogo antes desta pesquisa.

Essa foi a primeira experiência de hospitalização de Jorge. Ele foi internado para realizar cirurgia para implante de uma válvula no coração. Após a 
cirurgia, permaneceu cinco dias na UTI pediátrica do hospital e depois foi transferido para o leito da ala pediátrica. Quando se iniciou a pesquisa, Jorge interagia satisfatoriamente, não apresentava mais vulnerabilidades provenientes da cirurgia e todos seus remédios eram administrados oralmente.

Em casa, Jorge brincava com os primos que moram perto da sua residência. Antes da hospitalização, suas atividades preferidas eram jogar bola e andar de bicicleta. No ambiente hospitalar, Jorge tinha alguns brinquedos, frequentava a brinquedoteca e tinha acesso a desenhos para pintar e atividades educativas.

\section{(B) Relatos de eventos privados obtidos nas interações com e sem o uso de recurso lúdico}

Primeiro encontro: Rotina das crianças antes e durante a hospitalização

Na primeira parte do encontro com Davi (sem recurso), foram feitas perguntas sobre seu dia-dia no hospital, as quais ele respondeu sem grandes dificuldades.

Interação com Davi (D) - sem recurso lúdico

(P) Agora me conta um pouco do que tu faz aqui no hospital. Me conta como é teu dia-a-dia.

(D) Aziado..

(P) E o que o te leva a dizer que é aziado?

(D) É porque não tem nada para fazer.

(P) Entendi. Mas então o que tu faz aqui pra passar o tempo?

(D) O quê que eu faço? Ah... eu jogo joguinho no tablet, eu monto meu quebra-cabeça, tem também... eu brinco com as crianças do outro quarto e só.

(P) E você vai lá na brinquedoteca?

(D) Brinquedoteca eu não vou, por causa que eu posso pegar gripe.

(...)

(P) E tem alguma coisa que tu acha ruim no hospital?

(D) (Davi fica pensativo) É... eu não sei não.

(P) Tá bom, sem problemas.

No entanto, quando questionado sobre o que não gostava dentro do hospital, Davi se mostrou menos comunicativo, e percebeu-se, por meio de expressões faciais e corporais (desvio do olhar, expressão facial de confusão, retraimento dos ombros), que ele estava se sentindo desconfortável.

Encerrado o momento de interação sem recurso, disponibilizou-se o desenho e lápis giz de cera para que a criança pudesse pintar. Enquanto a criança pintava, restabeleceu-se o diálogo.

Interação com Davi (D) - com recurso lúdico

(P) O que você tá vendo no desenho?

(D) O que eu tô vendo?... Chovê... tem uma criança doente, ela tá deitada na cama... e tem um enfermeiro também.

(P) Legal. E o que o enfermeiro tá fazendo?

(D) É... ele tá cuidando dela [da criança]. Olha... ele tá pegando na mão dela.

(P) Hum... é verdade, é isso mesmo. Os enfermeiros vêm aqui te visitar também, Davi?

(D) Vêm, eles vêm quase toda hora.

(P) Ah é? E o que eles fazem quando vêm aqui?

(D) O que eles vêm fazer aqui?!... é ... ah eles me mede a temperatura... com o termômetro, eles botam bem aqui [axila]. E eles me dão remédio, também.

(P) Entendi. E eles fazem alguma coisa que tu não gosta?

(D) Se eles fazem... alguma coisa que eu não gosto?... é... eles me furam pra colocar soro. Dói... Eu não gosto.

(P) E tem alguma coisa que eles fazem que você gosta?

(D) Aaaah... eles conversam comigo, perguntam como é que tô... é... e só.

Pode-se perceber que ao estabelecer o diálogo com recurso lúdico, Davi respondeu as perguntas de forma mais fluente e contínua. Estar inserido em uma atividade prazerosa e estabelecer uma interação com menos contato visual podem ser elencada como variáveis importantes para as mudanças nas verbalizações. Del Prette \& Meyer (2012) afirmam que além das variáveis já citadas, estabelecer conversa com a criança enquanto ela brinca se torna menos aversivo porque essas interações pouco se assemelham às conversas mais "sérias" que são estabelecidas normalmente com os adultos.

Jorge verbalizou alguns eventos privados aversivos mesmo sem a atividade lúdica. Pode-se no- 
tar, no caso de Jorge, que o recurso lúdico também pode ser utilizado como instrumento complementar no acesso a eventos privados.

Interação com Jorge $(\mathrm{J})$ - sem recurso lúdico

(P) Tem alguma coisa que você gosta no hospital?

(J) Eu gosto do macarrão! E da comida!... Ah, e dos médicos e das criança que brinco no corredor.

(P) Tem alguma coisa que você não gosta?

(J) Eu não posso sair.

Interação com Jorge $(\mathrm{J})$ - com recurso lúdico

(P) O que tu tá olhando nesse desenho?

(J) Uma criança e o pai dela.

(P) Tem certeza? Olha com mais calma?

(J) Ah, não, não. É o enfermeiro que tá com a criança. A criança tá doente.

(...)

(P) Tem alguma coisa que eles (enfermeiros) fazem que você não gosta?

(J) Me dão injeção!

(P) Tem alguma coisa eles fazem que você gosta?

(J) O doutor O., ele que me operou, ele prometeu que ia me dar um carro.

No que diz respeito ao recurso utilizado nesse encontro, Del Prette \& Meyer (2012) o categoriza como "conversar decorrente". Essa atividade, segundo as autoras, envolve episódios verbais que estejam associados a alguma variável da atividade. Nesse encontro utilizou-se um desenho que se referia ao ambiente hospitalar para estabelecer uma comunicação menos aversiva com os participantes.

\section{Segundo encontro: Doença e suas implicações para as crianças}

Conforme descrito no método, no primeiro momento desse encontro utilizou-se o brincar e no segundo momento, a interação foi puramente verbal. $\mathrm{O}$ recurso escolhido foi o faz-de-conta utilizando cachorrinho de brinquedo chamado Clóvis.

Interação com Davi (D) - com recurso lúdico

(P) E como ele (Clóvis) tá se sentindo em relação a essa doença?

(D) Triste.

\section{(...)}

(P) E ele deixou de fazer alguma coisa porque tá com essa barriga doendo?

(D) Deixou. Não ficar correndo pela rua e não pode brincar com os outros cachorros.

(P) Tem mais alguma coisa que ele deixou de fazer?

(D) Ele não pode deitar no chão, senão vai pegar doença.

Interação com Davi (D) - sem recurso lúdico

(P) E o que tu sente por tá aqui no hospital?

(D) O que sinto?... Ah... Saudades dos meus irmãos e dos meus colegas da rua, e dos meus colegas do colégio também.

(...)

(P) Davi, eu tenho outra dúvida: tu deixa de fazer alguma coisa por causa da tua doença?

(D) Deixo. De não andar descalço no quintal, por causa que tem gato e cachorro.

(P) E o que tu acha dessa proibição?

(D) O que é eu acho? Que é chato... não posso brincar com meus irmãos.

É interessante identificar que houve similaridades entre os relatos com o uso de recurso lúdico e as verbalizações apresentadas sem o uso do recurso. As expressões "Não ficar correndo pela rua", "Não pode brincar com os outros cachorros" e "Ele não pode deitar no chão, senão vai pegar doença" se aproximam de "O que sinto? Saudades dos meus irmãos e dos meus colegas da rua, e dos meus colegas do colégio também" e "De não andar descalço no quintal, por causa que tem gato e cachorro".

Interação com Jorge $(\mathrm{J})$ - com recurso lúdico

(P) E o que ele (Clóvis) tá sentindo agora?

(J) Dor.

(...)

(P) E o que tu acha que ele tá pensando?

(J) Que ele quer sair do hospital.

(P) Entendi. Você me disse que Clóvis tá sentindo dor por causa da cabeça que tá quebrada. Mas me conta, ele deixou de fazer alguma coisa?

(J) Amham! Agora que ele tá doente ele não pode ficar brincando por aí com os amigos dele. 
Interação com Jorge $(\mathrm{J})$ - sem recurso lúdico

(P) Tu sente alguma dor agora?

(J) Não.

(P) Tu já sentiu?

(J) [Sinal positivo com a cabeça]

(P) E onde doía?

(J) [Aponta para o peito esquerdo, local da cirurgia]

(...)

(P) Tu deixou de fazer alguma coisa por causa dessa dor?

(J) Não. Eu andava pra todo lado, mas mamãe brigava comigo, dizia que era pra eu fica quieto, num deixava nem eu ir pra lá pra sala de brinquedos [brinquedoteca].

No caso de Jorge, as implicações mais estressoras da doença aconteceram durante o período pós-operatório. Durante o período de coleta, a criança já não apresentava debilitação física grave, mas os relatos mantêm aproximações entre a fantasia e as experiências vividas, como por exemplo, "Agora que ele tá doente ele não pode ficar brincando por aí com os amigos dele" e "Não. Eu andava pra todo lado, mas mamãe brigava comigo, dizia que era pra eu ficar quieto, num deixava nem eu ir pra lá pra sala de brinquedos [brinquedoteca]". Há outro evento privado que Jorge verbaliza durante a atividade lúdica: “(P) E o que tu acha que ele tá pensando? (J) Que ele quer sair do hospital". Esse evento privado é verbalizado em vários momentos nas outras interações, seja com atividade lúdica ou não.

O brincar de faz-de-conta utilizado no segundo encontro é classificado por Del Prette e Meyer (2012) como fantasiar. Essa categoria do brincar se caracteriza, segundo as autoras por serem "episódios verbais de interação lúdica com conteúdo de fantasia" (p.241). Ou seja, são atividades que extrapolam os limites físicos da brincadeira. Durante a atividade, a criança dá a objetos e personagens funções e características além daquelas que podem ser observadas na realidade.

As verbalizações de Jorge e Davi, com e sem o recurso de fantasia, mostram que eles deram ao brinquedo características que não existem na realidade, como por exemplo, dizer que o cachorrinho não pode brincar com seus amigos porque está doente. Situações como essas não existem efetivamen- te, mas fazem parte de suas histórias de vida. Eles colocaram sua história na fantasia. Esse comportamento é congruente com o que Skinner (1991) aponta sobre formação de imagens, que envolve a capacidade de ver algo que não está realmente presente, vê mesmo na ausência do objeto original. Por exemplo, quando se fala para alguém pensar em uma casa, a pessoa será capaz de ver a imagem de uma casa, apesar de a casa imaginada não estar ali realmente. No entanto, a imagem da casa irá variar, de pessoa pra pessoa, porque, segundo Skinner (1991), a história prévia de cada um irá condicionar a formação dessas imagens. Percebe-se então que foi a experiência de cada criança que controlou suas estórias fantasiosas.

\section{Terceiro encontro: Ambiente e procedimentos hospitalares}

Nesse encontro, o recurso lúdico foi utilizado na segunda metade da interação. No primeiro momento, interagiu-se com as crianças sem o brincar buscando identificar quais as perspectivas dos participantes sobre o ambiente e os procedimentos hospitalares.

No segundo momento, a pesquisadora propôs o jogo da trilha e esclareceu as regras. A proposta da atividade possibilitou que fossem feitas perguntas mais diretivas aos participantes. Por se tratar de uma atividade competitiva, estabeleceu-se uma motivação para a emissão das respostas sobre eventos privados: ao responder as perguntas, a criança poderia avançar no jogo e aumentar sua chance vencer.

Interação com Davi (D) - sem recurso lúdico (...)

(P) O que tu achas do quarto que tu fica?

(D) Desse quarto? Eu gosto dele.

(P) Que bom! E do banheiro?

(D) Do banheiro? [risada sem graça]

(P) Pode falar o que tu pensa, não vou brigar contigo.

(D) O banheiro acho horrível.

(P) Ah é? E o que faz o banheiro ser horrível assim?

(D) Porque o banheiro é todo sujo.

(P) Hum.. isso faz dele realmente um banheiro horrivel.

(...) 
(P) Tu já tomou soro?

(D) Já.

(P) Tu tomou onde? Me mostra.

(D) Aqui. (aponta para o braço)

(P) E o que tu achou disso?

(D) Ruim, não gosto de soro

Interação com Davi (D) - com recurso lúdico

(P) Davi, tenho uma dúvida: o que uma criança pensa quando o médico diz que ela tem que fazer cirurgia?

(D) Cirurgia?

(P) Humrum.

(D) O que ela pensa?

(P) Isso!

[Davi passa alguns segundos pensando]

(D) Ela só pensa na cirurgia. Eu pensava só na cirurgia quando eu ia fazer, mas só que não fiz.

(...)

(P) O que uma criança sente quando ela tem que tomar soro?

(D) O que ela sente? Horrível, não gosta... Porque entra na veia dos outros e arde.

(P) Entendi! Você me disse que já tomou soro. Você sentiu isso também?

(D) [Sinal positivo com a cabeça] E demora também.

(P) Ah é? Demora quanto tempo mais ou menos?

(D) Uns 200 tempos e ainda tava bem aqui

[Mostra com a mão que desceu bem pouco soro].

Nota-se um aumento na frequência do relato de eventos privados verbalizados por Davi sem o uso do recurso. Pode-se supor que o aumento na frequência está relacionado ao estabelecimento da relação de confiança entre a criança e a pesquisadora, relação essa que parece ter sido facilitada pelo uso de atividades lúdicas. Essa relação de confiança permite que o participante sinta-se mais confortável para relatar alguns eventos privados. Outra variável que pode ser acrescentada na justificativa é a postura da própria pesquisadora, que por já estar no terceiro encontro, estava mais a vontade, permitindo que a interação fluísse mais naturalmente.

A proposta inicial do jogo era que um jogador fizesse perguntas relacionadas à hospitalização para o outro, no entanto Davi expôs que não tinha nenhuma pergunta para fazer. Diante dessa negati- va, propôs-se que ao invés de fazer perguntas, ele dissesse para o outro jogador pagar a prenda. Davi concordou com a nova regra e à medida que o jogo avançou, ele se sentiu mais a vontade para explorar o controle dado a ele dentro da atividade. Durante as primeiras prendas, Davi aceitou as sugestões da pesquisadora, como por exemplo, "diga o nome de cinco desenhos animados que você gosta". A partir da terceira prenda, Davi criou suas próprias prendas, como por exemplo, "imite uma zebra" e "imite um cachorro dez vezes".

Além do relato de eventos privados, percebeu-se que essa atividade permitiu o estreitamente da relação entre participante e pesquisadora. Segundo Conte e Regra (2012), uma das funções dos recursos lúdicos é fazer com o psicólogo seja mais bem aceito pela criança, e isso ajuda no alcance dos objetivos terapêuticos.

O relato de eventos privados de Jorge mostrou-se satisfatório, tanto com o recurso lúdico, como sem o recurso. Pode-se supor que, assim como na interação com Davi, o estabelecimento e fortalecimento da relação, proporcionados em parte pelo desenvolvimento de atividades lúdicas, permitiu o aumento na frequência dessas verbalizações. No terceiro encontro, Jorge falou extensivamente sobre sua experiência com a cirurgia cardíaca, estadia na UTI e pós-operatório.

Interação com Jorge $(\mathrm{J})$ - sem recurso lúdico

(...)

(P) E me diz, o que tu pensou quando disseram que tu ia fazer cirurgia?

(J) [Risos sem graça] Fiquei com medo.

(P) E o que te deu medo?

(J) Pensei que ia morrer.

(P) Entendi, e tu lembra de alguma coisa da cirurgia?

(J) Botaram uma coisa aqui [rosto], botaram umas coisas aqui [peito]. Botaram primeiro no peito, depois botaram aqui [rosto], eu tirei, ai botaram de novo e eu agarrei no sono.

(P) E depois que tu acordou, o que tu lembra?

(J) Eu tava na UTI. Aí tentei falar, mas não consegui porque tava com a coisa [tubo de respiração], aí não consegui. Aí depois tiraram num dia [tubo], e no outro tiraram aquela coisa que tava no meu pintinho [dreno]. Aí depois vim pra cá 
[leito da enfermaria].

(P) E como era na UTI?

(J) Era bom. Era frio.

(...)

(P)...E tu olhou outras crianças lá na UTI?

(J) Sim. Tinha um monte de gente entubado.

Interação com Jorge (J) - com recurso lúdico

(P) O que uma criança sente quando ela vê injeção?

(J) Ela chora!

(P) E por que criança chora?

(J) Porque dói.

(...)

(P) O que uma criança acha de ficar num quarto

de hospital?

(J) Ruim. Só se for um quarto ruim.

(P) E o teu é o quê?

(J) Bom.

(P) E o que tem no teu quarto para ele ser bom?

(J) Porque tem colega lá e também dá para eu ver as pessoas lá fora. Eu vejo os barcos passando no mar. Vejo os seguranças...

No que diz respeito ao brincar utilizado, Soares et al. (2003) pontuam que o jogo é um recurso lúdico onde a criança pode se expressar de forma descontraída e geralmente prazerosa. Dessa forma, apesar de se estabelecer regras e de haver necessidade de responder a perguntas, o aspecto lúdico parece predominar e facilitar as verbalizações feitas pelos participantes.

\section{Quarto encontro: Relação com as pessoas presentes no hospital}

No quarto e último encontro, buscou-se identificar o que as crianças achavam das pessoas com as quais elas mantinham contato no ambiente hospitalar. Considerou-se importante investigar sobre este tema porque, conforme afirmam Dias et al. (2003), o ambiente hospitalar é um ambiente diferente do que a criança está acostumada, e ao se hospitalizar, ela se vê cercada de pessoas até então desconhecidas. Há a necessidade então de estabelecer relações com estas pessoas e com ambiente hospitalar. Caso essas relações não sejam saudáveis, elas podem ser fontes estressoras para a criança e tornar a hospitalização mais aversiva (Chiattone, 2003).

Segue abaixo, parte da interação sem uso de re- curso lúdico que foi estabelecida com Davi sobre o tema:

Interação com Davi (D) - sem recurso lúdico

(...)

(P) Davi, o quê que tu acha dos médicos daqui?

(D) São bacanas.

(P) Ah é?! E porque tu acha que eles são bacanas?

(D) Aaah... eles vem me visitar, conversam com mamãe... tem vez que vem um monte de médico pra me ver.

(...)

(P) E o que tu achas dos coleguinhas daqui do quarto?

(D) Hum... eu não sei.

(P) Tá bom, tudo bem.

(...)

(P) E dos acompanhantes, o quê que tu acha deles?

(D) O quê que eu acho deles?... também não sei, não.

(P) Tudo bem.

(...)

(P) Ontem tu me disse que as enfermeiras vem aqui te visitar. Mas tu não me disse o que tu acha delas...

(D) Eu acho ela boa. Tem vez que a enfermeira vem perguntar por mim.

(...)

(P) Quando eu entrei aqui, tinha uma moça limpando o banheiro. Tu conhece ela?

(D) Humrum... eu sei quem é.

(P) Ah tá. E o que tu acha dela e das pessoas que limpam o banheiro e o quarto?

(D) O quê que eu acho? Ham... não sei.

(P) Tá bom!

Após a interação sem o recurso, explicou-se a atividade onde ele deveria dar até cinco estrelas para cada pessoa representada na imagem. Uma estrela significa "não gosto" e cinco significava "gosto muito". Das avaliações feitas por Davi, algumas merecem destaque.

Para a imagem do médico, Davi deu duas estrelas.

(...) Eu coloquei só 2 por causa que uma vez um médico me furou e começou a fazer assim na 
minha veia, chega doeu [subtende-se pelo relato que o profissional estava tendo dificuldades em encontrar a veia do paciente].

Apesar de Davi ter considerado que foi um médico o autor desta ação aversiva, pressupõe-se, pelo conhecimento que se tem da prática hospitalar, que deve ter sido um enfermeiro ou um técnico em enfermagem. Independente disto, percebe-se que houve mudança na verbalização de suas avaliações e acréscimo de experiências aversivas em relação à figura do médico. $\mathrm{Na}$ interação sem recurso, Davi relata que considera os médicos como sendo " $b a-$ canas", e na interação com recurso pontua uma experiência aversiva vivenciada com um profissional que ele julga ser um médico. Considera-se que as informações relatadas com e sem recurso lúdico se complementam, uma vez que a criança parece possuir experiências reforçadoras e aversivas com os profissionais do hospital.

Aos acompanhantes das outras crianças internadas, Davi lhes deu três estrelas. E justificou:

\section{(...) \\ Por causa que quando elas vem visitar é.. elas não vêm conversar com a minha mãe. Elas fi- cam conversando só com elas. Aí vem visitar um colega da minha mãe, aí ele vem visitar e lê a Palavra pra todo mundo. Por isso que eu acho... por isso que não gosto muito.}

Ao longo das interações pode-se notar que Davi matinha uma relação bastante forte com a mãe e parece que esta relação foi crucial para a avaliação sobre os acompanhantes. Caso essa avaliação seja da própria criança e não apenas uma repetição que ela ouviu de alguém, pode ser uma demonstração que a criança percebe o meio em que está inserida e está sensível ao que acontece nele.

Ao pedir que avaliasse as pessoas responsáveis pela limpeza, Davi deu cinco estrelas, explicando "eles deixam o banheiro cheiroso" (SIC).

Houve mudanças significativas nas verbalizações de Davi sobre suas avaliações das pessoas com as quais convive nos dois momentos do encontro. Talvez a dificuldade em emitir respostas avaliativas negativas seja justificada por regras e uma possível história de punição ao fazer avaliação negati- vas de pessoas. Outra questão que pode justificar essa dificuldade pode ser a própria interação que se estabeleceu de "perguntas e respostas" entre a pesquisadora e o participante. Pode-se supor que a realização de perguntas diretivas tenha coagido o participante a emitir sua opinião de forma sincera.

As verbalizações das avaliações de Jorge sobre a maioria das pessoas com as quais convivera no hospital foram positivas, tanto na parte com recurso quanto na parte sem recurso, exceto a avaliação feita à equipe de limpeza:

Interação com Jorge $(\mathrm{J})$ - sem recurso lúdico (...)

(P) E o pessoal que vem limpar o quarto?

(J) Não, porque eles são [palavra não compreendida]

(P) Desculpa, eu não consegui entender. Eles são o quê?

(J) É que eles são trabalhadores do lixo.

(...)

$\mathrm{Na}$ atividade, Jorge (J) deu uma estrela para os mesmos profissionais:

(...)

(J) [risos sem graça] Vou dar uma estrela, não gosto deles.

Identificou-se pela justificativa dada por Jorge, que sua avaliação negativa não era resultado da relação estabelecida com esses profissionais no hospital. Sobre o assunto, a mãe de Jorge relatou que o paciente perguntou a uma profissional da limpeza por que ela não tinha estudado para virar médica. Dessa forma, sua avaliação negativa parece estar ligada regra de que os profissionais de serviços gerais são inferiores a outras profissões por serem "trabalhadores do lixo" (SIC). Apesar de não ser objetivo da pesquisa, buscou-se, durante a interação, trabalhar com a criança a importância que cada profissão tem.

Fazer avaliações negativas sobre as pessoas, culturalmente pode ser considerado como um comportamento reprovavél, o que pode gerar esquiva de emitir esse tipo de opinião, visando evitar possíveis punições. Outra variável que pode influenciar na dificuldade em avaliar é a falta de repertório para descrever suas opiniões. 
O recurso lúdico utilizado parece ter facilitado a exposição das avaliações ao quantificá-las: uma estrela para "não gosto" e cinco estrelas para "gosto muito". Ao transformar uma avaliação que era "qualitativa" em "quantitativa", a avaliação parece ter perdido parte da aversividade que outrora tivera.

\section{Considerações finais}

O foco deste estudo foi identificar a verbalização de eventos privados relacionados à hospitalização emitidos pelas crianças nos dois momentos da interação: com e sem recurso lúdico. A partir dos dados coletados, percebeu-se que os participantes conseguiram relatar alguns eventos privados na interação com o recurso lúdico que não conseguiram emitir na interação puramente verbal. Além de relatar eventos privados que possivelmente não seriam verbalizados, o brincar também funcionou para complementar informações coletadas anteriormente sem a utilização do recurso. A criança consegue verbalizar alguns eventos privados sem o recurso, mas por conta das próprias limitações de comunicação comuns a idade da criança ou por se tratar de um evento privado aversivo, ela pode apresentar dificuldade em relatar de forma clara ou completa. Assim, ao utilizar o brincar, pode-se investigar sobre o que fora dito anteriormente e obter mais informações.

Além dessas conclusões, pôde-se perceber que o brincar contribui indiretamente para a verbalização de privados. O desenvolvimento de atividades lúdicas durante as interações estabeleceu e fortaleceu mais facilmente a relação entre pesquisadora e participantes. Esse fortalecimento da relação, por sua vez, favoreceu o relato de privados sem os recursos lúdicos. Notou-se ainda, que o estabelecimento de uma relação de confiança se mostra como um fator importante na facilitação da verbalização de privados, principalmente quando se trata de crianças que apresentam dificuldades em se comunicar.

Pode-se acrescentar aos ganhos dessa pesquisa, o feedback positivo dado pelas mães, que eram as responsáveis legais dos participantes, sobre o desenvolvimento das atividades. Antes do último encontro, elas foram avisadas sobre a finalização do estudo. Ambas mostraram interesse na continuação dos encontros e lamentaram o fim das atividades. Segundo as responsáveis, os participantes haviam relatado que gostavam das atividades e que se divertiam durante o momento. Além disso, elas consideraram positivas as interações, pois ao brincar, os participantes se afastavam um pouco da rotina hospitalar. O feedback das responsáveis vem reforçar achados como o de Hostert et al. (2014), que pontuam que a distração proporcionada pela prática lúdica faz desta uma atividade prazerosa, que proporciona alívio de dor e estresse dentro do ambiente hospitalar.

Nesta pesquisa, os recursos lúdicos utilizados nas interações foram confeccionados pelas pesquisadoras especificamente para o estudo, considerando o contexto hospitalar. Considera-se que foi relevante a utilização destes recursos, pois, provavelmente, recursos adaptados à situação hospitalar podem ter colaborado para a verbalização de eventos privados, que outras atividades lúdicas, não focadas no ambiente hospitalar, possivelmente não evocariam. Isso demonstra a importância do psicólogo se reinventar de acordo com o contexto em que está inserido.

Deve-se ponderar, no entanto, que a pesquisadora que realizou a coleta não possuía experiência com interações psicoterápicas, o que fez com que algumas de suas perguntas e colocações induzissem as crianças a certas respostas. Além disso, considera-se que algumas verbalizações das crianças deveriam ter sido melhor investigadas para conclusões mais precisas. Tal consideração é importante inclusive para enfatizar a relevância do treino e permanente aperfeiçoamento dos terapeutas nas práticas psicoterápicas, com e sem o uso do brincar.

Finalmente, considerando as limitações desta pesquisa, percebe-se a importância do desenvolvimento de outros estudos, principalmente sobre intervenções que abordem os eventos privados relacionados à hospitalização. Acredita-se que dessa forma, pode-se ampliar o conhecimento sobre o uso de recursos lúdicos no acesso e intervenção de eventos privados, bem como proporcionar repertório teórico e técnico para melhorar o trabalho com crianças que estão inseridas em ambiente hospitalar. 


\section{Referências}

Barros, D. M. S. \& Lustosa, M. A. (2009). A ludoterapia na doença crônica infantil. Revista $S B P H$, 12(2), 114-136.

Baum, W. B. (2019). Compreender o behaviorismo: comportamento, cultura e evolução. (3a ed). F.A. Cassas \& D. Bueno (Trads.). Porto Alegre: Artmed.

Botega, N. J. (2012). Prática Psiquiátrica no Hospital Geral: interconsulta e emergência. (3a ed). Porto Alegre: Artmed.

Carvalho, A. M. \& Begnis, J. G. (2006). Brincar em unidades de atendimento pediátrico: aplicações e perspectivas. Psicologia em Estudo, 11 (1), 109117. doi: 10.1590/S1413-73722006000100013

Chiattone, H. B. C. (2003) A criança e a hospitalização. In V. A. Angerami-Camon (Org.). A psicologia no hospital. (2a ed). (pp. 23-100). São Paulo: Pioneira Thomson Learning.

Conte, F. C. de S. \& Regra, J. A. G. (2012). A Psicoterapia Comportamental Infantil: novos Aspectos. In E. F. M. Silvares (Org.). Estudos de caso em Clínica Comportamental infantil. (7a ed.). (Vol. 1, pp. 79-138). São Paulo: Papirus.

Costa, N. (2002). A subjetividade sob a ótica Behaviorista Radical: interpretação, aspectos polêmicos e manejo terapêutico. In N. Costa (Org.). Terapia analítico-comportamental: dos fundamentos filosóficos à relação com o modelo cognitivista. (pp. 16-26). Santo André: ESETec.

Del Prette, G. (2006). Terapia analítico-comportamental infantil: relações entre o brincar e comportamentos da terapeuta e da criança (Dissertação de mestrado). Instituto de Psicologia, Universidade de São Paulo, São Paulo.

Del Prette, G. \& Meyer, S. B. (2012). O brincar como ferramenta de avaliação e intervenção na clínica analítico-comportamental infantil. In $\mathrm{N}$. B. Borges \& F. A. Cassas (Orgs.). Clínica analítico-comportamental: aspectos teóricos e práticos. (pp. 239-250). Porto Alegre: Artmed.

Del Rey, D. (2012). O uso de recursos lúdicos na avaliação funcional em clínica analítico-comportamental infantil. In N. B. Borges \& F. A. Cassas (Orgs.). Clínica analítico-comportamen- tal: aspectos teóricos e práticos. (pp. 233-238). Porto Alegre: Artmed.

Dias, R. R., Baptista, M. N., \& Baptista, A. S. D. (2003). Enfermaria de pediatria: Avaliação e intervenção psicológica. In M. N. Baptista, M. N. \& R. R. Dias. (Orgs.). Psicologia hospitalar: teoria, aplicações e casos clínicos. (pp. 53-73). Rio de Janeiro: Guanabara Koogan.

Doca, F. N. P. (2009). A psicologia pediátrica em hospitais universitários brasileiros. (Dissertação de Mestrado). Instituto de Psicologia, Universidade de Brasília, Brasília.

Ferreira, E. A. P. (2006) Adesão ao tratamento em psicologia pediátrica. In M. A. Crepaldi, M. B. M. Linhares \& G. B. Perosa (Eds.). Temas em psicologia pediátrica (pp. 147-190). São Paulo: Casa do Psicólogo.

Gadelha, Y. A. \& Menezes, I. N. (2004). Estratégias lúdicas na relação terapêutica com crianças na terapia comportamental. Universitas Ciências da Saúde, 2(1), 39-55. doi: 10.5102/UCS. V2I1.523

Guerrelhas, F., Bueno, M., \& Silvares, E. F. M. (2000). Grupo de Ludoterapia Comportamental X Grupo de Espera Recreativo Infantil. Revista Brasileira de Terapia Comportamental e Cognitiva, 2(2), 157-169.

Hostert, P. C. C. P., Enumo, S. R. F., \& Loss, A. B. M. (2014). Brincar e problemas de comportamento de crianças com câncer de classes hospitalares. Revista Psicologia: Teoria e Prática, 16(1), 127-140. doi: 10.15348/1980-6906/psicologia. v16n1p127-140.

Marçal, J. V. de S. (2010). Behaviorismo radical e prática clínica. In A. K. C. R. de Farias. Análise comportamental clínica: aspectos teóricos e estudos de caso. (pp. 30-48). Porto Alegre: Artmed.

Mitre, R. M. A \& Gomes, R. (2004). A promoção do brincar no contexto da hospitalização infantil como ação de saúde. Ciência \& Saúde Coletiva, 9(1), 147-54. doi: 10.1590/S141381232004000100015.

Moraes, E. O. \& Enumo, S. R. F. (2008). Estratégias de enfrentamento da hospitalização em crianças avaliadas por instrumento informatizado. Psico-USF, 13(2), 221-231. doi: 10.1590/S141382712008000200009 
Moreira, M. B. \& Hanna, E. S. (2012). Bases Filosóficas e Noção de Ciência em Análise do Comportamento. In M. M. C. Hubner \& M. B. Moreira. Temas clássicos da psicologia sob a ática da Análise do Comportamento. (pp.1-19) Rio de Janeiro: Guanabara Koogan.

Naves, A. R. C. X. \& Ávila, R. R. (2018). A formulação comportamental na terapia analítico-comportamental infantil. In A.K.C.R. de Farias, F. N. Fonseca., \& L. B. Nery (Orgs.). Teoria e formulação de casos em análise comportamental clínica. (pp. 185-213). Porto Alegre: Artmed.

Regra, J. A. G. (2000). Formas de trabalho na psicoterapia infantil: mudanças ocorridas e novas direções. Revista Brasileira de Terapia Comportamental e Cognitiva, 2(1), 79-101.

Rico, V. V., Golfeto, R., \& Hamasaki, E. I. M. Sentimentos. (2012). In M. M. C. Hubner \& M. B. Moreira. Temas clássicos da psicologia sob a ática da Análise do Comportamento. (pp. 8899). Rio de Janeiro: Guanabara Koogan.

Simões, A. L. A., Yamamoto, L. R., Silva, L. C., \& Silva, P. A. (2010). Satisfação de clientes hospitalizados em relação às atividades lúdicas desenvolvidas por estudantes universitários. Revista Eletrônica de Enfermagem, 12(1), 107112. doi: $10.5216 /$ ree.v12i1.9528

Skinner, B. F. (1961). A análise de termos operacionais psicológicos. H. Guilhardi \& P. Queiroz (Trads.). Appleton: New York. (Trabalho publicado originalmente em 1945). Recuperado a partir de http://www.itcrcampinas.com.br/pdf/ skinner/analise_operacional.pdf

Skinner, B. F. (1991). Questões Recentes na Análise Comportamental. (5a ed). Campinas: Papirus.

Skinner, B. F. (2003). Ciência e comportamento humano. (11a ed). J. C. Todorov, \& R. Azzi, (Trads.). São Paulo: Martins Fontes. (Trabalho publicado originalmente em 1953).

Skinner, B. F. (2006). Sobre o Behaviorismo. (10a ed.) M. P. Villalobos (Trad.) São Paulo: Cultrix. (Trabalho publicado originalmente em 1974).

Soares, M. R. Z, Moura, C. B. de, \& Prebrianchi, H.B. (2003). Estratégias lúdicas para intervenção terapêutica com crianças em situação clínica e hospitalar. In M. Z. Brandão, F. C. S. Conte, F. S. Brandão, Y. K. Ingberman, C. B. Moura, V. M. Silva., \& S. M. Oliane (Orgs.). Sobre compor- tamento e cognição: clínica pesquisa e aplicação. (Vol. 12, pp. 312-323). Santo André: ESETec.

Tourinho, E. Z. (2009). Dimensões da abordagem Analítico-Comportamental para o problema da Subjetividade. In Z. E. Tourinho. Subjetividade e relações comportamentais. (pp. 95-147). São Paulo: Paradigma.

\section{Informações do Artigo}

Histórico do artigo:

Submetido em: 31/08/2018

Primeira decisão editorial: 29/12/2018

Versão definitiva aceita em: 09/04/2019

Editor Associado: Denis Roberto Zamignani 